\title{
Review of the European reference framework for sustainable cities
}

\author{
Amanda K. Winter ${ }^{1}$ (D)
}

Received: 24 August 2018 / Accepted: 18 October 2018 / Published online: 12 November 2018

(C) The Author(s) 2018

\begin{abstract}
This review examines the European Reference Framework for Sustainable Cities, an online framework for use by urban practitioners to evaluate and visualize the sustainability profile and priorities of an urban sustainability plan, policy, or initiative. This review presents recognized benefits and challenges from a testing phase of the framework, how it fits into the European Urban Agenda, and more broadly how indicator frameworks connect to the global urban sustainability context.
\end{abstract}

Keywords Urban sustainability · sustainability indicators · EU Urban Agenda - sustainable development

The European Reference Framework for Sustainable Cities (RFSC, see CEREMA 2016) is an online framework for use by urban practitioners to evaluate and visualize the sustainability profile and priorities of an urban sustainability plan, policy, or initiative. To develop this framework, a working group of EU representatives and the Council of European Municipalities and Regions selected 30 actions based on (1) their relevance to the EU Urban Agenda and (2) the accessibility and availability of relevant data needed to assess the indicators. The EU Urban Agenda (European Commission n.d.) emerged from the 2007 Leipzig Charter (European Commission 2007), where common urban development principles were agreed upon, and the 2008 Marseille Declaration, where a tool to implement those principles (the RFSC) was agreed upon. The EU Urban Agenda seeks to streamline existing EU regulations with urban concerns to address socioeconomic inequalities and improve community wellbeing.

The RFSC is managed by the French government's Centre of Expertise on Risk, Environment, Mobility and Planning (CEREMA) and the framework's 30 actions are broken into five dimensions: spatial, governance, social, economic, and environmental

Amanda K. Winter

amanda.winter@nottingham.ac.uk

1 School of Sociology and Social Policy, University of Nottingham, Room B12, Lenton Hurst, University Park, Nottingham NG7 2RD, UK 
(see Table 1). Users can select any or all actions. Each action has a set of indicators to input data, and this will create a profile based on the RFSC or the 17 Sustainable Development Goals.

The benefits of the RFSC appear to be its accessibility (free for anyone in the world to use with a simple registration and without commitment), flexibility (chose any or all indicators for a specific plan or the entire city), and the visual outputs (radar charts) for cities of any size. As noted in a report on the testing phase with 66 cities, users found the RFSC helpful to track progress, identify weaknesses, conduct initial assessments, and develop coordination strategies between different municipal departments and government levels (Van Dijken et al. 2012). For example, two departments in the La Rochelle (FR) municipality separately applied all of the RFSC indicators to several environmental initiatives (eco-districts, biodiversity planning, and the Agenda 21 plan) yet arrived at different outcomes, and this prompted communication across sectors. Some cities in the testing phase applied the RFSC to their overall sustainability plans and some applied it to specific initiatives: Maia (PT) assessed a river water quality project and Velenje (SI) developed a bicycle scheme. The testing phase revealed that city size was a factor for uptake of the tool: small and medium sized cities showed more interest as they lacked in-house planning staff and frameworks compared to larger cities. The early version of the RFSC was criticized for not accommodating different sized cities, being too complex, and time-consuming (Van Dijken et al. 2012).

The broader context into which this framework sits is a societal trend of global urbanization and climate change, where cities have been tasked to economically

Table 1 Reference framework for sustainable cities: dimensions and actions

\section{Spatial dimension}

1. Develop sustainable urban planning and land use

2. Ensure spatial equality

3. Encourage territorial resilience

4. Preserve and enhance urban, architectural and cultural heritage

5. Promote high quality and functionality of public spaces and living environment

6. Develop alternative and sustainable mobility

\section{Economic dimension}

19. Stimulate green growth and the circular economy

20. Promote innovation and smart cities

21. Ensure connectivity

22. Develop employment and a resilient local economy

23. Encourage sustainable production and consumption

24. Foster cooperation and innovative partnerships

\section{Governance dimension}

7. Ensure an integrated territorial strategy

8. Foster sustainable administration and financial city management

9. Implement a process for assessment and on-going improvement

10. Increase citizen participation

11. Strengthen governance in participation

12. Facilitate capacity building and networking

\section{Environmental dimension}

25. Mitigate climate change

26. Protect, restore and enhance biodiversity and ecosystems

27. Reduce pollution

28. Adapt to climate change

29. Manage natural materials resources sustainably and prevent waste

30. Protect, preserve and manage water resources

\section{Social dimension}

13. Ensure social inclusion

14. Ensure social and intergenerational equity

15. Build up a supply of housing for everyone

16. Protect and promote health and well-being

17. Improve inclusive education and training

18. Promote culture and leisure opportunities 
develop, improve local environmental conditions, accommodate growing populations, and provide better quality of life. This is reflected in the RFSC's promotional slogan: 'creating green, inclusive, and attractive cities.' Thus, urban practitioners have sought to measure and track progress in different sectors that often fall under the wide-ranging notion of 'sustainability' (see The European Commission's 2018 Report on 'Science for Environmental Policy' for descriptions of popular indicator frameworks). A map of users on the RFSC website shows that the framework is employed around the world; this is also seen as a tool to encourage knowledge exchange. Similar to this is the STAR Community Rating System to assess local sustainability and share best practices in the US (STAR Communities n.d.).

This practice of plan assessment via indicators often provokes debates of power, public engagement/participation, and the politics of choosing what to measure and how. Since funding is often tied to measurement, indicators that are difficult to quantify, and in addition possibly politically risky to confront, such as those in the RFSC's Social and Governance Dimensions, may have funding challenges. Also unresolved in the RFSC is the fact that pursuing progress in one indicator may have unintended consequences and contradict progress in another indicator. One example in which this may be the case is with respect to mitigating climate change compared to adapting to climate change (see the RFSC's Environmental Dimension). Kaika (2017, p. 94) warns that indicator programs have existed at least since the 1987 UN Brundtland Report and the lack of progress toward sustainable cities in this period should give indicators advocates pause. To Kaika, this failure "should have also made us wise enough to stop claiming that global socio-environmental equality, social welfare or value creation can be reduced to indicators." She also warns of a trend in the past decade by which such indicator programs conflate 'smart' and 'green' with 'sustainable', without good reason. Despite these critiques, significant efforts to internationally promote and institutionalize the use of indicators to measure sustainability in cities continue. This trend and the RFSC offer a learning opportunity to better understand, compare, and track urban sustainability initiatives in Europe and beyond.

Acknowledgments This study was funded by the Leverhulme Trust, grant number RP 2013-SL-015.

\section{Compliance with ethical standards}

Conflict of interest The author declares no conflict of interest.

Open Access This article is distributed under the terms of the Creative Commons Attribution 4.0 International License (http://creativecommons.org/licenses/by/4.0/), which permits unrestricted use, distribution, and reproduction in any medium, provided you give appropriate credit to the original author(s) and the source, provide a link to the Creative Commons license, and indicate if changes were made.

\section{References}

CEREMA (2016). The Reference Framework for Sustainable Cities. http://rfsc.eu/. Accessed 1 July 2018. European Commission (n.d.). EU Urban Agenda. https://ec.europa.eu/futurium/en/urban-agenda. Accessed 1 July 2018. 
European Commission (2007). Leipzig Charter on Sustainable European Cities. http://ec.europa.eu/regional_ policy/archive/themes/urban/leipzig_charter.pdf. Accessed 1 July 2018.

Kaika, M. (2017). 'Don’t call me resilient again!': the New Urban Agenda as immunology ... or ... what happens when communities refuse to be vaccinated with 'smart cities' and indicators. Environment and Urbanization, 29(1), 89-102.

Science for Environment Policy (2018). "Indicators for sustainable cities." In-depth Report 12. Produced for the European Commission DG Environment by the Science Communication Unit, UWE, Bristol. http://ec.europa.eu/environment/integration/research/newsalert/pdf/indicators_for_sustainable_cities_ IR12 en.pdf. Accessed 1 July 2018.

STAR Communities (n.d.). http://www.starcommunities.org/. Accessed 1 July 2018.

United Nations. (1987). Our Common Future - Brundtland Report. Oxford: Oxford University Press.

Van Dijken, K., Dorenbos, R. and Kamphof, R. (2012). The Reference Framework for Sustainable Cities (RFSC): Testing results and recommendations. http://www.eukn.eu/fileadmin/Lib/files/EUKN/2013 /Final\%20report\%20Nicis\%20testing\%20RFSC.pdf. Accessed 1 July 2018. 